\title{
Orientação familiar e seus efeitos na gagueira infantil
}

\section{Familiar counseling and its effects on childhood stuttering}

\author{
Cristiane Moço Canhetti de Oliveira ${ }^{1}$, Cristiane Naomi Yasunaga ${ }^{2}$, Luciana Tavares Sebastião ${ }^{3}$, \\ Edinalva Neves Nascimento ${ }^{4}$
}

\begin{abstract}
RESUMO
Objetivo: Verificar a contribuição da orientação familiar de curto prazo na fluência da fala de crianças com gagueira. Métodos: Participaram 20 díades de crianças com gagueira e familiares. Os procedimentos foram realizados em três etapas: avaliação da fluência, orientações familiares e reavaliação da fluência. A avaliação inicial da fluência foi realizada para caracterizar a tipologia e a frequência das disfluências antes das orientações. A orientação familiar foi realizada em duas sessões, enfatizando os comportamentos verbais e não verbais da família que podem promover a fluência na criança. A reavaliação da fluência ocorreu depois de trinta dias, utilizando-se os mesmos procedimentos da avaliação inicial. Foi aplicado o Teste dos Postos Sinalizados de Wilcoxon, para medir o grau de significância da diferença entre as informações obtidas nas duas fases. Resultados: No que se refere à tipologia, a análise comparativa das duas avaliações mostrou que, dentre os seis tipos de disfluências comuns, quatro diminuíram, e, dentre os seis tipos de disfluências gagas, cinco apresentaram redução. No que se refere à frequência das rupturas, $70 \%$ das crianças tiveram uma diminuição na porcentagem de descontinuidade de fala, e $80 \%$ no total de rupturas gagas. Conclusão: A orientação fonoaudiológica realizada com familiares de crianças com gagueira favoreceu a promoção da fluência na fala da criança, mostrando-se relevante na área da fluência infantil.
\end{abstract}

Descritores: Gagueira; Criança; Aconselhamento; Família

\section{INTRODUÇÃO}

Todos os falantes podem apresentar disfluências comuns na fala, que parecem evidenciar incertezas linguísticas relacionadas à formulação das frases ou pronúncia das palavras $^{(1)}$.

Vários fatores justificam a variabilidade desta ocorrência, entre eles, o nível de demanda da linguagem em termos linguísticos e cognitivos ${ }^{(2-3)}$, o grau de familiaridade com o tópico, bem como as interrupções e velocidade da conversação do interlocutor ${ }^{(4-5)}$.

Trabalho realizado no Departamento de Fonoaudiologia da Faculdade de Filosofia e Ciências da Universidade Estadual Paulista "Júlio de Mesquita Filho" - UNESP - Marília (SP), Brasil.

(1) Doutora, Professora do Departamento de Fonoaudiologia da Faculdade de Filosofia e Ciências da Universidade Estadual Paulista "Júlio de Mesquita Filho" - UNESP - Marília (SP), Brasil.

(2) Acadêmica do Curso de Fonoaudiologia da Faculdade de Filosofia e Ciências da Universidade Estadual Paulista "Júlio de Mesquita Filho" UNESP - Marília (SP), Brasil.

(3) Doutora, Professora do Departamento de Fonoaudiologia da Faculdade de Filosofia e Ciências da Universidade Estadual Paulista "Júlio de Mesquita Filho" - UNESP - Marília (SP), Brasil.

(4) Pós-graduanda (Doutorado) em Educação na Universidade Estadual Paulista Júlio de Mesquita Filho" - UNESP - Marília (SP), Brasil.

Endereço para correspondência: Cristiane Moço Canhetti de Oliveira. R. Santa Helena, 1967/23, Jd. Estoril, Marília (SP), Brasil, CEP: 17514-410.

E-mail: cmcoliveira@terra.com.br

Recebido em: 6/1/2009; Aceito em: 3/7/2009
Além das disfluências comuns, a fala pode ser interrompida pelas disfluências atípicas ou gagas, que são comportamentos descritos como característicos de indivíduos com gagueira ${ }^{(6-8)}$.

A gagueira é um distúrbio da fluência caracterizada por interrupções no fluxo da fala do indivíduo, impossibilitando, em alguns momentos, a produção da fala contínua, suave e sem esforço. Esta desordem apresenta maior prevalência durante a infância ${ }^{(8-9)}$. Fatores biológicos, psicológicos e sociais interagem de uma forma complexa neste distúrbio, e vale destacar que a interação familiar é apenas um dos aspectos envolvidos nesta tríade. Portanto, gagueira é uma desordem de aspecto multidimensional ${ }^{(9)}$, na qual inúmeros fatores podem interferir no desenvolvimento da fluência infantil, como o histórico mórbido pré-peri-pós-natal, o histórico familial, o fator ambiental, as capacidades linguísticas e cognitivas da criança. Estes fatores estabelecem numerosas relações entre si e para compreender a gagueira é preciso construir um raciocínio dialético que articule a dimensão biológica, com a psicológica e com a social ${ }^{(10)}$.

Nesta perspectiva multifatorial, um dos modelos mais conhecidos e que tem influenciado o processo de intervenção da gagueira é o Modelo da Demanda e Capacidade ${ }^{(11-12)}$, no qual a gagueira é vista como um resultado de um desequilíbrio entre as demandas ambiental e social e a capacidade da criança. A capacidade para uma criança produzir uma fala fluente dependeria de habilidades motoras, habilidades para a produção da linguagem, maturidade e estabilidade emocional, e nível do 
desenvolvimento cognitivo. A meta da terapia proposta por este modelo é aumentar a capacidade e reduzir a demanda nas áreas motora, emocional, linguística e cognitiva ${ }^{(12)}$.

A demanda pode ser representada pelos fatores ambientais que estão associados com o estresse comunicativo (vocabulário excessivamente elaborado, conversação numa velocidade aumentada, questionamentos frequentes, interrupções verbais, competição para falar, correção dos padrões de fala, frases extensas e complexas), estresse interpessoal (rotina familiar inconsistente, demanda aumentada para a capacidade da criança, comparação e competição entre irmãos, falta de tempo com os pais) e estresse das situações vivenciadas (conflitos na família, datas comemorativas, feriados, eventos inesperados, mudanças na rotina, doenças, experiências traumáticas).

Comportamentos inadequados dos familiares em relação à gagueira infantil, como, por exemplo, o não respeito à troca de turnos e fala rápida, têm um importante papel no desenvolvimento da gagueira infantil ${ }^{(13-15)}$. Estes comportamentos disponibilizam pouco tempo para a criança transmitir sua mensagem, representando um aumento na demanda linguística e motora da fala.

As atitudes familiares com crianças fluentes, gagas e com risco para o desenvolvimento da gagueira foram comparadas. Os resultados mostraram que quanto maior o risco, pior era a qualidade destes comportamentos, havendo diferença estatisticamente significante entre os grupos ${ }^{(9)}$.

As reações negativas dos interlocutores da criança com gagueira, como, por exemplo, completar as palavras e desviar o olhar, podem interferir negativamente no prognóstico terapêutico ${ }^{(16-19)}$, bem como prejudicar a comunicação ${ }^{(19)}$. Estas atitudes poderão colaborar para o desenvolvimento de uma baixa auto-estima e uma crença na incapacidade articulatória, ocasionando, em alguns casos, a fuga de situações comunicativas. Porém, estes comportamentos verbais e não verbais dos interlocutores não são os únicos determinantes no prognóstico, que é resultado da somatória de inúmeros fatores, como predisposição ou vulnerabilidade de uma pessoa para o distúrbio, fatores de caráter emocional e os de caráter social (a fala gaguejada frequentemente gera ansiedade e medo de falar reforçando o auto-conceito de mal falante e também a gagueira).

A gagueira infantil pode desaparecer sem a intervenção, no entanto, pode também persistir até a fase adulta. Se, por um lado, grande parte das crianças com gagueira irá se recuperar espontaneamente ${ }^{(9,13,20)}$, por outro lado, é comprovado que a intervenção precoce nesta desordem apresenta resultados melhores e mais rápidos. Neste sentido, a proposta de orientação familiar torna-se muito interessante, tendo em vista que é um procedimento de baixo custo que poderá auxiliar ou maximizar o potencial que a criança apresenta de recuperação da gagueira.

A mediação do fonoaudiólogo na orientação familiar em relação à gagueira infantil é, portanto, fundamental, pois permite discutir os procedimentos que serão realizados, assim como promover atividades que viabilizam atitudes favoráveis em relação à fluência ${ }^{(9,21-23)}$.

A redução da velocidade de fala na atividade dialógica com a criança é um importante aspecto a ser enfocado, já que existem evidências de que terapias que incluem a diminuição na velocidade de fala facilitam a obtenção da fluência na pessoa que gagueja ${ }^{(14,21,24-25)}$. O ritmo de fala acelerado do interlocutor representa um aumento da demanda do sistema de compreensão de fala da criança, que, por sua vez, precisa compreender o que foi dito. Além do que, também aumenta a demanda do sistema linguístico responsável pela elaboração e produção da resposta que terá que ser dada ao interlocutor ${ }^{(26)}$.

Libcombe é um programa destinado ao tratamento da gagueira, no qual o fonoaudiólogo realiza visitas domiciliares e orienta a família sobre os procedimentos de intervenção, no início do surgimento das disfluências ${ }^{(27-28)}$. Vários resultados positivos foram apresentados pelos autores deste programa, evidenciando o importante papel dos familiares na intervenção fonoaudiológica com crianças que apresentam gagueira.

Desta forma, o objetivo deste trabalho foi verificar a contribuição da orientação familiar de curto prazo na fluência da fala de crianças com gagueira.

\section{MÉTODOS}

Este trabalho foi encaminhado para apreciação do Comitê de Ética da Universidade Estadual Paulista Júlio de Mesquita Filho (UNESP), sendo por ele aprovado, protocolo 430/2005. Ressalta-se que todos os princípios éticos foram cumpridos conforme versa a Resolução 196/96 do Conselho Nacional de Saúde.

Esta pesquisa foi realizada no contexto do Programa de Intervenção da Disfluência Infantil (PIDI) do Centro de Estudos da Educação e Saúde (CEES) da Faculdade de Filosofia e Ciência (FFC) da UNESP, Campus de Marília, São Paulo, Brasil.

Participaram 20 díades de crianças com gagueira e familiares $(\mathrm{N}=40)$. As crianças eram de ambos os gêneros, sendo $13(65 \%)$ meninos e sete $(35 \%)$ meninas, com idade entre quatro e dez anos (média de 6,5 anos). Todas frequentavam escola, tendo a maioria sido encaminhada pelo Estágio de Fonoaudiologia Educacional.

Os critérios de inclusão dos participantes no estudo foram: ser falante nativo do Português Brasileiro, não apresentar déficits neurológico, auditivo, cognitivo e visual, bem como apresentar queixa familiar de gagueira e uma porcentagem mínima de $3 \%$ de disfluências gagas na avaliação da fluência inicial.

Os familiares eram adultos alfabetizados, com algum grau de parentesco com a criança.

\section{Materiais}

Foram utilizados impressos pré-elaborados, como carta de apresentação da pesquisa, termo de consentimento livre e esclarecido do participante e protocolo de avaliação da fluência ${ }^{(29)}$. Também foi utilizada filmadora, fitas VHS, figuras ilustrativas de ação e folheto explicativo sobre as orientações fonoaudiológicas (Anexo 1).

\section{Procedimentos}

Os procedimentos da pesquisa foram realizados em três etapas: avaliação da fluência, orientação fonoaudiológica e reavaliação da fluência. 


\section{Avaliação da fluência}

A avaliação clínica inicial da fluência foi realizada para confirmar o diagnóstico de gagueira, bem como caracterizar a tipologia e a frequência das disfluências, de acordo com o Teste de Fluência do $\mathrm{ABFW}^{(29)}$. Foi apresentada uma figura aos participantes e dada a seguinte ordem: "Por favor, olhe essa figura e me fale tudo o que você quiser sobre ela". O discurso só foi interrompido por perguntas e/ou comentários, nos casos em que houve a necessidade de incentivar a produção do discurso para obtenção de 200 sílabas fluentes (número de sílabas fluentes necessárias para a análise da amostra). Cada criança foi filmada durante aproximadamente dez minutos.

Após a coleta de fala dos participantes, as mesmas foram transcritas na íntegra, considerando-se as sílabas fluentes e não fluentes ${ }^{(29)}$. Posteriormente, foi realizada a análise da amostra da fala e caracterizada a tipologia das disfluências ${ }^{(29)}$, de acordo com a seguinte descrição:

- Disfluências comuns: hesitações, interjeições, revisões, palavras não terminadas, repetições de palavra, repetições de segmentos e repetições de frases.

- Disfluências gagas: repetições de sons, repetições de sílabas, prolongamentos, bloqueios, pausas e intrusões.

Para caracterizar a frequência das rupturas, foram utilizadas as seguintes medidas ${ }^{(29)}$ : porcentagem de descontinuidade de fala ou taxa de rupturas no discurso, e porcentagem de disfluências gagas ou taxa de rupturas gagas.

Para participar da pesquisa a criança precisava apresentar no mínimo 3\% de disfluências gagas, o que foi considerado como um dos critérios diagnósticos do distúrbio.

\section{Orientação fonoaudiológica}

A orientação fonoaudiológica consistiu de duas sessões de 40 minutos, realizadas com apoio de um folheto explicativo especialmente elaborado para o PIDI (Anexo 1). Os tópicos das orientações foram selecionados em função da literatura ${ }^{(9,21)}$ e da experiência clínica dos pesquisadores em orientações familiares de crianças gagas. As principais informações contidas no folheto foram referentes à promoção da fluência na fala da criança por meio de algumas sugestões de interação comunicativa, modelos de fala e de linguagem, e atitudes adequadas frente à gagueira.

Na primeira sessão, inicialmente, foram explicadas as manifestações fonoaudiológicas da criança, a presença das disfluências comuns e gagas e o motivo da ocorrência das rupturas. Num segundo momento, explicou-se cada tópico de orientação do folheto, utilizando-se exemplos de situações de comunicação, bem como modelos verbais e não verbais promotores da fluência. Houve uma preocupação na coerência do conteúdo da orientação com os aspectos suprasegmentais da fala que foram oferecidos aos familiares. Por exemplo, o examinador falava de forma suave, quando orientava sobre a suavidade dos contatos articulatórios.

$\mathrm{Na}$ segunda sessão, as orientações versaram sobre a importância da redução da velocidade de fala, da suavidade dos contatos articulatórios, bem como da fala contínua por parte dos familiares, tornando-se modelos para a criança e, consequentemente, facilitando a obtenção da fluência. Os familiares foram estimulados a imitar o modelo oferecido pela pesquisadora, treinando a redução da velocidade de fala, suavidade e continuidade em algumas palavras e frases. $\mathrm{O}$ familiar também observou a interação comunicativa entre o fonoaudiólogo e a criança, para conhecer, na prática, os modelos verbais e não verbais que promovem a fluência e que podem ser oferecidos à criança. No final desta sessão, o familiar interagiu com a criança na presença do fonoaudiólogo, colocando em prática as orientações recebidas.

As orientações foram realizadas utilizando-se linguagem coloquial, para que pudessem ser bem compreendida pelos familiares. Também foram realizadas discussões sobre como viabilizar a adoção dos procedimentos discutidos nas orientações, e como estabelecer novos comportamentos promotores da fluência na rotina familiar. $\mathrm{O}$ folheto explicativo foi entregue aos familiares como um instrumento de consulta e auxílio, buscando, assim, facilitar o papel de multiplicador das orientações no ambiente domiciliar, o qual os familiares deveriam desempenhar junto aos outros pares de conversação da criança.

\section{Reavaliação da fluência}

A reavaliação da fluência foi realizada depois de trinta dias. Foram utilizados os mesmos procedimentos da avaliação da fluência inicial ${ }^{(29)}$, ou seja, interação com a criança com figuras ilustrativas durante a filmagem, transcrição e análise da amostra de fala.

\section{Análise dos dados}

As informações obtidas na avaliação inicial e na reavaliação receberam um tratamento estatístico, com utilização das frequências absolutas e relativas. Aplicou-se o Teste dos Postos Sinalizados de Wilcoxon, para se medir o grau de significância das diferenças entre as variáveis.

\section{RESULTADOS}

\section{Caracterização dos participantes}

O Quadro 1 sintetiza a caracterização dos participantes da pesquisa. Participaram 20 crianças na faixa etária de quatro anos e cinco meses a dez anos e zero meses de idade, de ambos os gêneros, e com o tempo mínimo de duração das disfluências de 12 meses. Um total de $45 \%$ dos participantes apresentou histórico familial positivo para a gagueira. Os familiares participantes foram 11 mães, cinco pais e quatro avós que conviviam diariamente com a criança.

\section{Tipologia das disfluências}

Os dados da tipologia das disfluências foram apresentados e comparados nas duas avaliações realizadas. A legenda a seguir foi utilizada para interpretação das tabelas e figuras: $\mathrm{H}$ = hesitação; I = interjeição; Rv = revisão; RS = repetição de segmento; $\mathrm{RF}=$ repetição de frase; $\mathrm{RP}=$ repetição de palavra.

A Figura 1 mostra a frequência absoluta das disfluências comuns, apresentadas pelas crianças na avaliação inicial e na reavaliação. 
Quadro 1. Caracterização dos participantes

\begin{tabular}{|c|c|c|c|c|c|}
\hline Participante & Idade & Gênero & $\begin{array}{l}\text { Tempo de duração } \\
\text { das disfluências }\end{array}$ & $\begin{array}{c}\text { História familial } \\
\text { de gagueira }\end{array}$ & $\begin{array}{c}\text { Grau de parentesco do familiar } \\
\text { que recebeu orientação }\end{array}$ \\
\hline 1 & $8 a 8 m$ & $M$ & $17 \mathrm{~m}$ & negativo & pai \\
\hline 2 & $8 a 10 m$ & $\mathrm{~F}$ & $15 \mathrm{~m}$ & negativo & pai \\
\hline 3 & $7 a 9 m$ & $M$ & $13 m$ & negativo & mãe \\
\hline 4 & $5 a 7 m$ & $\mathrm{~F}$ & $12 m$ & positivo & mãe \\
\hline 5 & $7 a$ & $\mathrm{~F}$ & $24 m$ & negativo & avó \\
\hline 6 & $4 a 11 m$ & $\mathrm{~F}$ & $18 m$ & negativo & pai \\
\hline 7 & $6 a 8 m$ & $\mathrm{~F}$ & $13 m$ & positivo & mãe \\
\hline 8 & $6 a 4 m$ & $M$ & $18 m$ & negativo & avó \\
\hline 9 & $5 a 2 m$ & $M$ & $15 \mathrm{~m}$ & positivo & mãe \\
\hline 10 & $5 a 8 m$ & $\mathrm{~F}$ & $22 m$ & positivo & mãe \\
\hline 11 & $4 a 4 m$ & $\mathrm{~F}$ & $14 \mathrm{~m}$ & negativo & avó \\
\hline 12 & $6 a 8 m$ & $M$ & $25 \mathrm{~m}$ & positivo & mãe \\
\hline 13 & $4 a 5 m$ & $M$ & $12 m$ & positivo & mãe \\
\hline 14 & $10 a$ & $M$ & $36 \mathrm{~m}$ & positivo & pai \\
\hline 15 & $8 a 10 m$ & $M$ & $29 m$ & negativo & mãe \\
\hline 16 & $5 a 5 m$ & $M$ & $16 m$ & negativo & pai \\
\hline 17 & $6 a$ & $M$ & $19 m$ & positivo & mãe \\
\hline 18 & $7 a 1 m$ & $\mathrm{M}$ & $31 \mathrm{~m}$ & negativo & avó \\
\hline 19 & $5 a 3 m$ & $\mathrm{~F}$ & $19 m$ & negativo & mãe \\
\hline 20 & 7a10m & $\mathrm{F}$ & $33 m$ & positivo & mãe \\
\hline
\end{tabular}

Legenda: $a=$ anos; $m=$ meses; $M=$ masculino; $F=$ feminino

A análise da tipologia mostrou que todas as crianças $(\mathrm{N}=20)$ apresentaram disfluências comuns na avaliação inicial. Observou-se, em ordem decrescente, interjeições, hesitações, repetições de frases, repetições de segmentos, repetições de palavras e revisões. Na reavaliação, foram observadas, em ordem decrescente, repetições de palavras, interjeições, hesitações, repetições de segmentos, revisões e repetições de frases.

A análise comparativa entre as duas avaliações mostrou que, quatro dentre os seis tipos avaliados, apresentaram uma diminuição na ocorrência de rupturas na reavaliação: hesitações, interjeições, repetições de segmentos e repetições de frases. Por outro lado, houve aumento na quantidade de revisões e repetições de palavras. A Tabela 1 mostra a análise estatística dos dados.
Foi aplicado o Teste dos Postos Sinalizados de Wilcoxon, com o propósito de se analisar as diferenças entre o total de disfluências comuns observadas na avaliação inicial e na reavaliação. Os resultados mostraram que a diferença foi estatisticamente significante $(*)$ para hesitação, revisão, repetição de frase e repetição de palavra.

A Figura 2 mostra a frequência absoluta das disfluências gagas apresentadas pelas crianças na avaliação inicial e na reavaliação.

A análise mostrou que todas as crianças $(\mathrm{N}=20)$ apresentaram disfluências gagas na avaliação inicial. Numa sequência decrescente, as disfluências apresentadas foram o prolongamento, a repetição de sílaba, o bloqueio, a repetição de som, a pausa e a intrusão. Na reavaliação, as disfluências mais ocorrentes foram as repetições de sílabas, os prolongamentos,

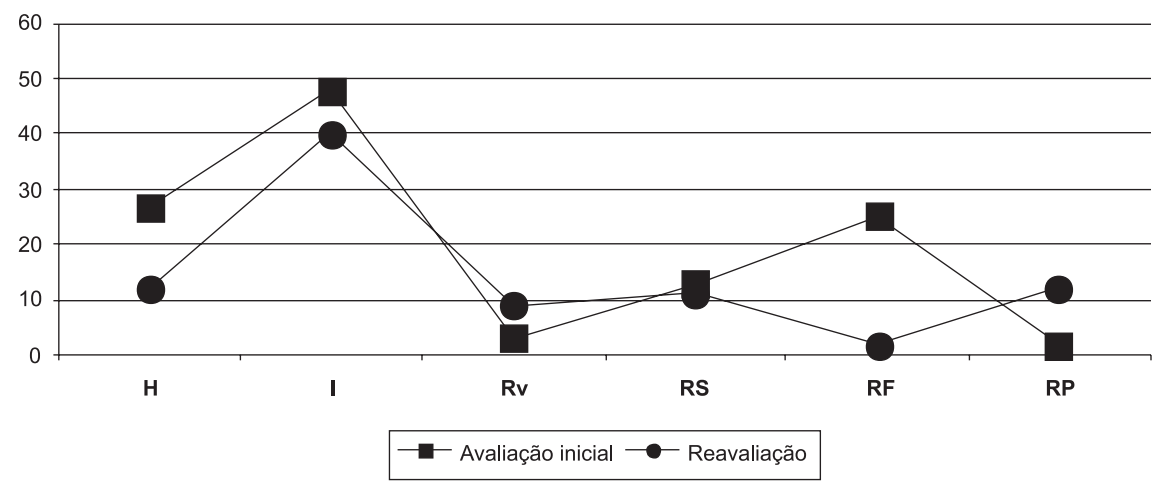

Legenda: $\mathrm{H}$ = hesitação; I = interjeição; $\mathrm{Rv}$ = revisão; $\mathrm{RS}$ = repetição de segmento; $\mathrm{RF}$ = repetição de frase; $\mathrm{RP}=$ repetição de palavra

Figura 1. Frequência absoluta das disfluências comuns apresentadas pelas crianças na avaliação inicial e na reavaliação 
Tabela 1. Comparação entre a avaliação inicial e a reavaliação quanto às disfluências comuns

\begin{tabular}{lcccccc}
\hline Avaliação & $\mathrm{H}$ & $\mathrm{I}$ & $\mathrm{Rv}$ & $\mathrm{RS}$ & $\mathrm{RF}$ & $\mathrm{RP}$ \\
\cline { 2 - 7 } & Média $\pm \mathrm{DP}$ & Média $\pm \mathrm{DP}$ & Média $\pm \mathrm{DP}$ & Média $\pm \mathrm{DP}$ & Média \pm DP & Média \pm DP \\
\hline Avaliação inicial & $1,35 \pm 1,5$ & $2,4 \pm 2,11$ & $0,15 \pm 0,37$ & $0,65 \pm 0,99$ & $1,25 \pm 1,07$ & $0,6 \pm 1,35$ \\
Reavaliação & $0,6 \pm 8,49$ & $2,0 \pm 2,85$ & $0,5 \pm 0,8$ & $0,55 \pm 0,76$ & $0,1 \pm 0,31$ & $2,9 \pm 1,8$ \\
Valor de $\mathrm{p}$ & $\mathrm{p}=0,025^{*}$ & $\mathrm{p}=0,534$ & $\mathrm{p}=0,034^{*}$ & $\mathrm{p}=0,66$ & $\mathrm{p}=0,001^{*}$ & $\mathrm{p}=0,003^{*}$ \\
\hline
\end{tabular}

Legenda: $\mathrm{H}$ = hesitação; I = interjeição; Rv = revisão; RS = repetição de segmento; $\mathrm{RF}$ = repetição de frase; RP = repetição de palavra; $\mathrm{DP}$ = desvio-padrão

* Valores estatisticamente significantes

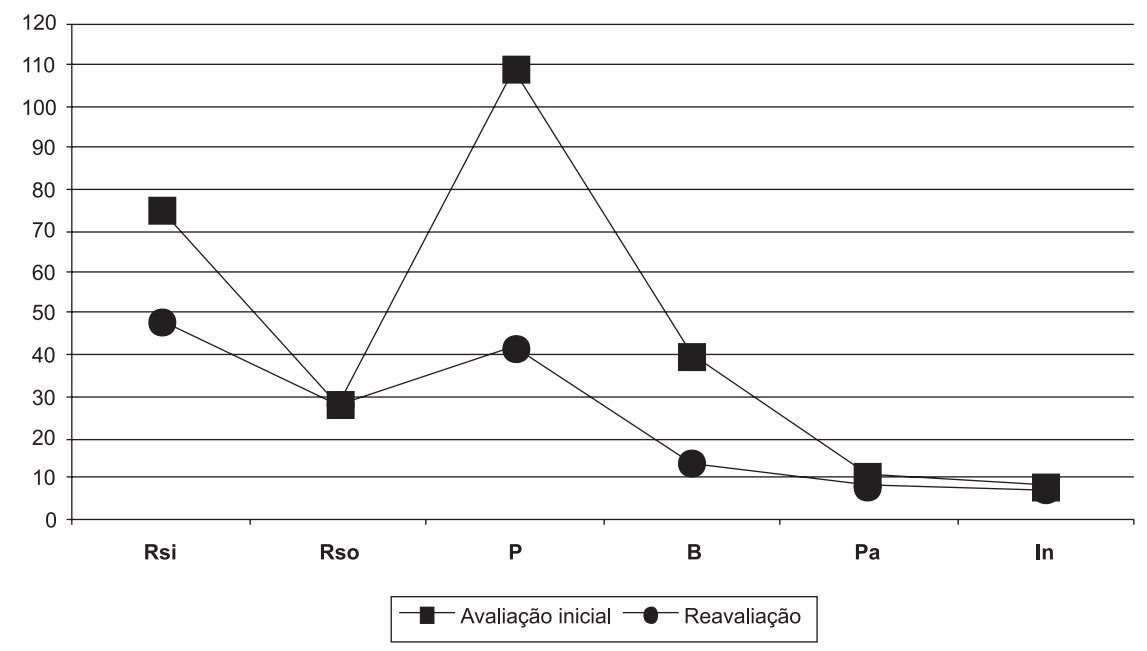

Legenda: $\mathrm{Rsi}=$ repetição de sílaba; $\mathrm{Rso}=$ repetição de som; $\mathrm{P}=$ prolongamento; $\mathrm{B}=$ bloqueio; $\mathrm{Pa}=$ pausa; $\ln =$ intrusão

Figura 2. Frequência absoluta das disfluências gagas apresentadas pelas crianças na avaliação inicial e na reavaliação

as repetições de sons, os bloqueios, as pausas e as intrusões. Vale ressaltar que uma das crianças não apresentou disfluência gaga na reavaliação.

$\mathrm{Na}$ análise comparativa, verificou-se que, dentre os seis tipos avaliados, cinco deles apresentaram uma diminuição na ocorrência de rupturas, sendo elas, a repetição de sílaba, o prolongamento, o bloqueio, a pausa e a intrusão. O número de repetições de sons foi o mesmo antes e após as orientações. A Tabela 2 apresenta a análise estatística dos dados.

Aplicou-se o Teste dos Postos Sinalizados de Wilcoxon, para analisar as diferenças entre o total de disfluências gagas nas duas avaliações. Os resultados mostraram que a diferença foi estatisticamente significante (*) para a repetição de sílaba, o prolongamento e o bloqueio.

\section{Frequência de rupturas}

A frequência de rupturas foi calculada segundo a metodologia utilizada(29) ${ }^{(29}$ considera a porcentagem de descontinuidade de fala e a porcentagem de disfluências gagas.

A Figura 3 mostra a frequência relativa da descontinuidade de fala, apresentada pelas crianças na avaliação inicial e na reavaliação.

Houve uma grande variabilidade na porcentagem de descontinuidade de fala, observada nas duas avaliações (Figura 3). Nota-se que dois sujeitos (10\%) apresentaram a mesma porcentagem, em ambas as condições. Após as orientações familiares, quatro crianças $(20 \%)$ tiveram um aumento na porcentagem de descontinuidade de fala, e 14 crianças $(70 \%)$ tiveram a frequência diminuída.

A Figura 4 mostra a frequência relativa das disfluências gagas, apresentadas pelas crianças na avaliação inicial e reavaliação.

Apenas uma criança (5\%) apresentou a mesma porcentagem de disfluências gagas, na avaliação inicial e na reavaliação (Figura 4). Os dados obtidos na reavaliação mostraram um aumento das disfluências em três crianças (15\%) e uma diminuição predominante em dezesseis (80\%) delas. Tais

Tabela 2. Comparação entre a avaliação inicial e a reavaliação quanto às disfluências gagas

\begin{tabular}{|c|c|c|c|c|c|c|}
\hline \multirow[t]{2}{*}{ Avaliação } & Rsi & Rso & $\mathrm{P}$ & B & $\mathrm{Pa}$ & In \\
\hline & Média \pm DP & Média \pm DP & Média \pm DP & Média \pm DP & Média \pm DP & Média $\pm \mathrm{DP}$ \\
\hline Avaliação inicial & $3,75 \pm 2,29$ & $1,4 \pm 1,6$ & $5,45 \pm 6,57$ & $2 \pm 2,49$ & $0,6 \pm 1,1$ & $0,4 \pm 1,35$ \\
\hline Reavaliação & $2,4 \pm 2,01$ & $1,4 \pm 1,93$ & $1,95 \pm 1,7$ & $0,7 \pm 1,38$ & $0,4 \pm 0,68$ & $0,35 \pm 0,67$ \\
\hline Valor de $p$ & $p=0,021^{*}$ & $p=0,975$ & $p=0,001^{*}$ & $\mathrm{p}=0,010^{*}$ & $p=0,641$ & $p=0,861$ \\
\hline
\end{tabular}

Legenda: $\mathrm{Rsi}=$ repetição de sílaba; Rso = repetição de som; $\mathrm{P}=$ prolongamento; $\mathrm{B}=$ bloqueio; $\mathrm{Pa}=$ pausa; In = intrusão; $\mathrm{DP}=$ desvio-padrão 


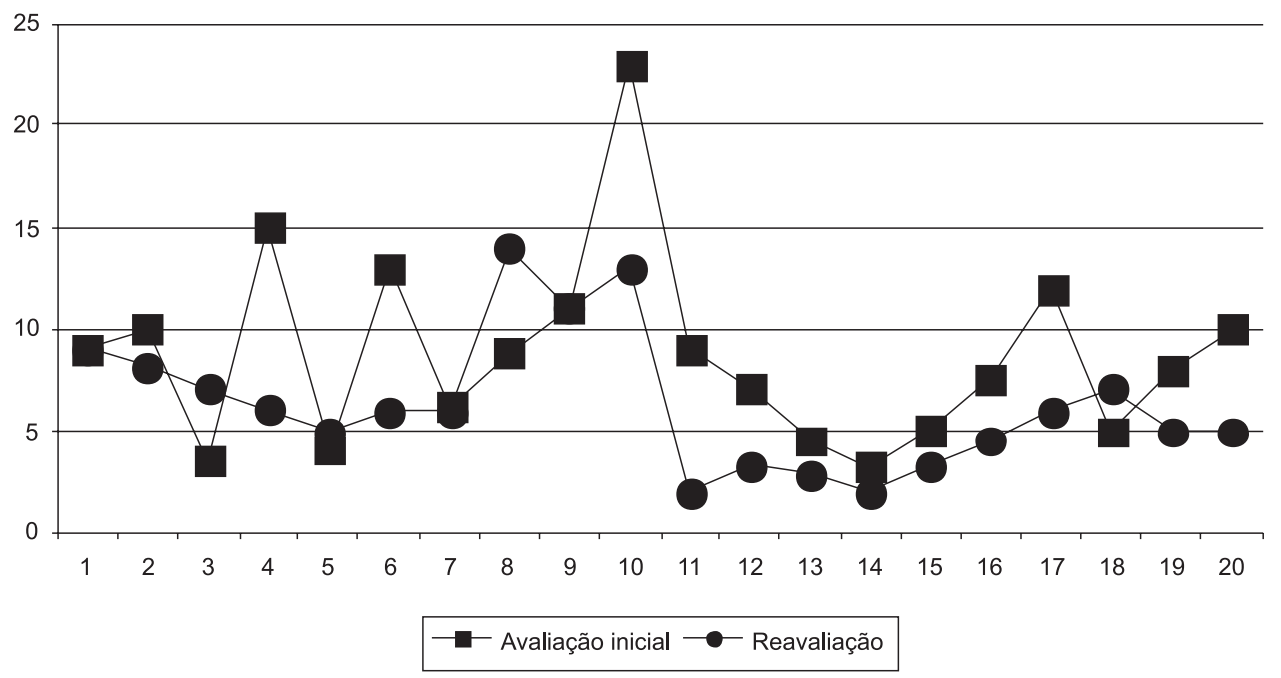

Figura 3. Frequência relativa da descontinuidade de fala apresentada pelas crianças na avaliação inicial e na reavaliação

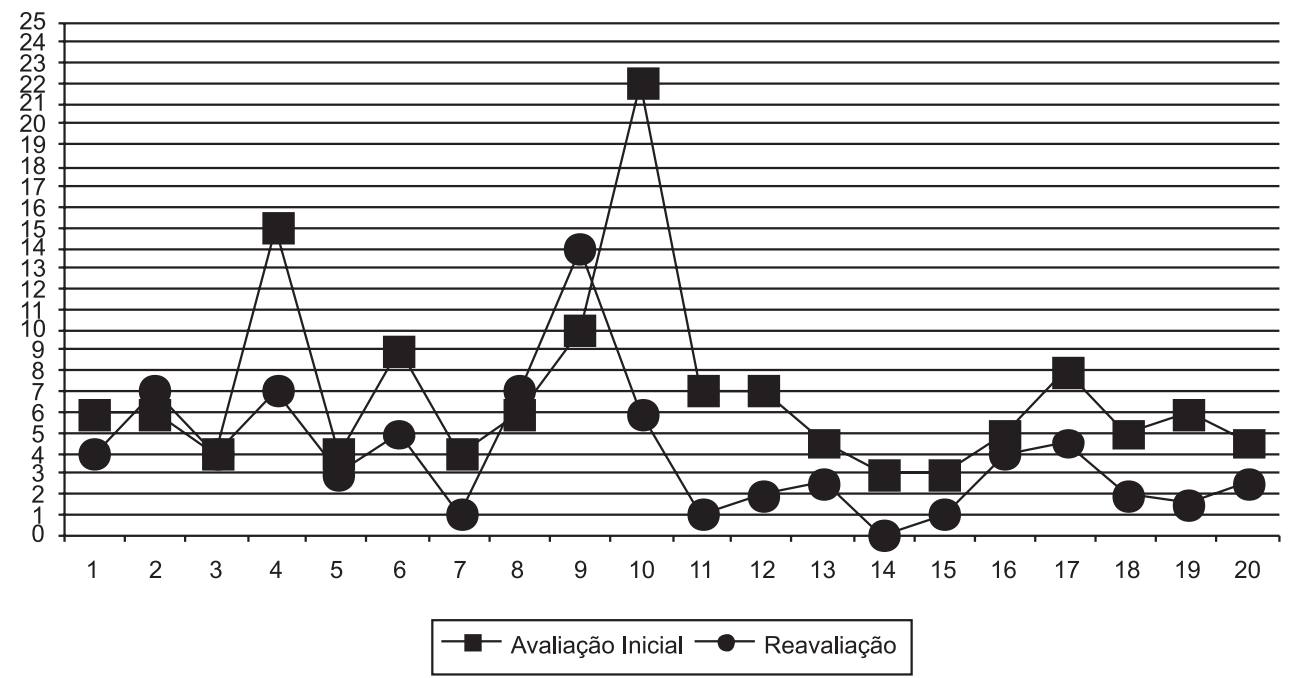

Figura 4. Frequência relativa das disfluências gagas apresentadas pelas crianças na avaliação inicial e na reavaliação

dados sugerem que a realização das orientações contribuiu para a diminuição da ocorrência de disfluência na maioria dos casos investigados.

Quanto ao gênero dos participantes, nota-se que a redução das disfluências gagas ocorreu com maior prevalência no gênero feminino (87,5\%), em relação ao masculino (75\%).

A Tabela 3 apresenta a análise estatística da frequência das rupturas.

A análise estatística mostrou diferença significativa nas duas medidas analisadas. Os dados obtidos indicam que houve uma redução no total de rupturas das crianças com

Tabela 3. Comparação da avaliação inicial e da reavaliação quanto à descontinuidade na fala e disfluências gagas

\begin{tabular}{lcc}
\hline Avaliação & $\begin{array}{c}\text { Porcentagem de } \\
\text { descontinuidade }\end{array}$ & $\begin{array}{c}\text { Porcentagem de } \\
\text { disfluências gagas }\end{array}$ \\
\hline Média \pm DP & Média \pm DP \\
\hline Realiação inicial & $8,38 \pm 4,35$ & $7,21 \pm 3,44$ \\
Valor de $p$ & $5,35 \pm 3,27$ & $3,34 \pm 1,97$ \\
\hline
\end{tabular}

Legenda: DP = desvio-padrão gagueira, após as orientações fonoaudiológicas oferecidas aos familiares.

\section{DISCUSSÃO}

Este estudo teve como objetivo verificar o efeito da orientação familiar de curto prazo na fluência da fala de crianças com gagueira. Apesar do grupo de crianças ter apresentado uma faixa etária extensa (quatro a dez anos de idade), todos os casos foram diagnosticados como gagueira, e, o tempo de duração mínima das disfluências foi de 12 meses, evidenciando a persistência da desordem.

A proporção masculino/feminino foi de 1,5:1, menor que a razão de gênero frequentemente encontrada na literatura $(4: 1)^{(13,20,25)}$. Esta diferença pode ter ocorrido devido à faixa etária do grupo. A razão masculino/feminino é menor na infância do que na fase adulta, possivelmente porque o gênero feminino apresenta uma maior probabilidade de recuperar espontaneamente da gagueira ${ }^{(9,20,25)}$. Nossos achados corroboram a literatura, tendo em vista que a maior ocorrência de diminuição das disfluências gagas ocorreu nos participantes do gênero feminino, em relação ao masculino. 
Aproximadamente metade dos casos (45\%) apresentou histórico familial positivo para a gagueira, dado este coerente com os achados sobre os fatores etiológicos da desordem ${ }^{(13)}$. Observou-se, no entanto, que os casos que tinham predisposição genética não se diferenciaram como um grupo, com relação às disfluências na reavaliação. Este dado é coerente com o modelo multifatorial para explicar a natureza da gagueira, no qual os fatores biológicos interagem de uma forma complexa com os fatores ambientais ${ }^{(9-10)}$.

Este estudo não visou investigar se existia ou não a redução da gravidade da gagueira, pois a orientação foi de curto prazo. O objetivo foi analisar a possível mudança na fluência das crianças após a intervenção.

Como observado na literatura ${ }^{(2)}$, houve uma grande variabilidade na ocorrência das disfluências entre os indivíduos, tanto na avaliação inicial como na reavaliação. Este achado está de acordo com a própria definição de fluência, que destaca a sua variabilidade em função do dia, das emoções, do domínio sobre o tema da conversação e das diferentes situações de fala do dia-a-dia ${ }^{(29)}$.

A partir da comparação das disfluências manifestadas na avaliação inicial da fluência, e na reavaliação realizada após as orientações, verificou-se uma tendência de diminuição das disfluências comuns e gagas. Porém, este resultado deve ser analisado com cuidado, pois crianças apresentam a possibilidade de recuperação espontânea da $\operatorname{gagueira}^{(8-9,13,20)}$.

Os dados obtidos na avaliação inicial e na reavaliação indicaram a presença de disfluências comuns na fala das crianças, o que corrobora a literatura de que todo falante apresenta este tipo de disfluência ${ }^{(1,2,7)}$. Nossos achados mostraram também que a frequência de disfluências comuns foi bastante variada nos participantes. Como observado na literatura, vários fatores podem justificar a variabilidade da ocorrência das disfluências comuns, como o nível da linguagem em termos cognitivos e linguísticos, o grau de familiaridade com o tópico, as interrupções e a velocidade de conversação do interloucutor ${ }^{(2-5)}$.

Os resultados mostraram, no total das disfluências comuns, uma diminuição na ocorrência destas rupturas na reavaliação, que pode ser resultado das possíveis mudanças do modelo de fala dos familiares, bem como do próprio desenvolvimento da fluência da criança. Acredita-se que a partir das orientações houve uma redução da demanda motora e linguística, que pode ter colaborado para promover a fluência.

Além das rupturas comuns, a fluência de todas as crianças participantes foi interrompida por disfluências gagas, antes das orientações, como era esperado, devido ao quadro de gagueira $^{(2,6-8)}$. Na análise comparativa, as tipologias repetição de sílaba, prolongamento, bloqueio, pausa e intrusão apresentaram menor ocorrência na reavaliação, sendo que a diferença foi estatisticamente significativa para a repetição de sílaba, o prolongamento e o bloqueio.

Vale ressaltar que a tipologia repetição de som não diminuiu na reavaliação. Num estudo comparativo entre crianças gagas e fluentes $^{(9)}$, a repetição de som foi a disfluência gaga de menor ocorrência nas crianças fluentes, reforçando que esta tipologia é uma característica típica da gagueira infantil. De maneira geral, a ocorrência de disfluências gagas
$(3,34 \%)$ após a orientação continuou num valor considerado acima do limite para um padrão fluente $(3 \%)^{(20)}$. Estes achados qualitativo e quantitativo da reavaliação da fluência reforçam que a gagueira infantil requer uma intervenção direta com a criança, para promover a fluência de uma forma efetiva, ou seja, para diminuir a porcentagem de disfluências gagas em valores considerados dentro dos parâmetros da normalidade.

Conforme o Modelo de Demanda e Capacidade ${ }^{(11-12)}$, acreditamos que a redução da demanda nas diferentes áreas motora, linguística, cognitiva e emocional por parte dos familiares, pode interferir positivamente no prognóstico da gagueira infantil. As orientações familiares precisam ser embasadas na literatura científica ${ }^{(9,22,24)}$, e complementam a terapia fonoaudiológica na promoção da fluência da fala da criança, pois a criança com gagueira também necessita de uma intervenção que aumente sua capacidade de falar fluentemente.

Os resultados desse estudo são importantes tanto para os clínicos quanto para os pesquisadores, tendo em vista que mostram os possíveis efeitos da orientação familiar e, ao mesmo tempo, reforçam a necessidade da terapia fonoaudiológica. Existe na literatura um programa que trabalha especificamente com os familiares de crianças gagas, que também relata vários resultados positivos ${ }^{(27-28)}$, no entanto, esta investigação mostrou os efeitos de uma orientação familiar breve, que pode ser amplamente utilizada nos atendimentos públicos e particulares.

Quanto ao conteúdo das orientações familiares, os estudos revelaram alguns comportamentos, como não respeito à troca de turnos, fala rápida, desvio de olhar e completar a fala da criança ${ }^{(13-19)}$, que podem prejudicar o desenvolvimento da fluência e devem ser abordados na abordagem familiar. Acreditamos que a eficácia da orientação familiar, no entanto, não está apenas associada ao conteúdo, mas também ao uso de estratégias nas quais devem ser promovidas outras atividades além das orientações verbais, como, por exemplo, observação da interação comunicativa entre terapeuta e criança e prática das novas habilidades ${ }^{(21-23)}$.

A redução das porcentagens de descontinuidade de fala e de disfluências gagas, na reavaliação, mostrou que a fluência é muito variável e sofre influência de inúmeros fatores. Este estudo apontou algumas alterações na fluência de crianças com gagueira, que podem ocorrer após as orientações familiares, porém, devido a sua natureza multimensional ${ }^{(9)}$, acreditamos que vários fatores também interferiram para o aumento da fluência na fala da criança. Certamente, a predisposição genética à gagueira, as variáveis linguística, cognitiva, motora e emocional, e a influência ambiental interagiram de uma forma complexa e colaboraram para as alterações na fluência encontradas nesta investigação.

\section{CONCLUSÕES}

Os dados obtidos neste estudo sugerem que as orientações fonoaudiológicas oferecidas aos familiares de crianças com gagueira contribuíram para reduzir a frequência de descontinuidade da fala e de disfluências gagas nas crianças avaliadas. O rigor científico e a experiência clínica utilizada no planejamento do conteúdo e nas estratégias de orientação 
otimizaram os resultados alcançados. Porém, devido à natureza multimensional da gagueira, os resultados encontrados na reavaliação podem ter sofrido interferência de outros fatores, como orgânicos e psicológicos, que interagiram com os ambientais.

Acreditamos que esta pesquisa poderá propiciar reflexões entre clínicos e pesquisadores da área, tendo em vista que as orientações fonoaudiológicas foram medidas importantes de intervenção, que precisariam ser valorizadas e adotadas nos diversos campos de trabalho. No entanto, este tipo de intervenção deve ser associado à terapia fonoaudiológica para favorecer a obtenção de resultados mais satisfatórios.

A orientação familiar tem sua implicação social, uma vez que a comunidade é beneficiada com a redução das filas de espera das instituições públicas de saúde. Além disso, a formação de agentes multiplicadores das orientações realizadas, certamente contribuirá para a disseminação das informações discutidas, e poderá também nortear os comportamentos verbais e nãoverbais adotados com outros familiares gagos. Vale ressaltar que o prognóstico terapêutico na gagueira infantil também pode ser favorecido com as orientações familiares, tanto em termos de qualidade dos resultados a serem obtidos, como em redução do tempo de terapia.
Entendemos que a generalização dos achados deste estudo é limitada, uma vez que não analisamos a correlação da avaliação inicial e da reavaliação com as variáveis de idade, gênero, tempo de duração das disfluências, componente genético ou não do distúrbio, bem como a avaliação da linguagem, dos processos fonológicos e outros dados que poderão contribuir para identificar diferentes grupos de crianças com gagueira. Entretanto, novas pesquisas podem ser realizadas para investigar a combinação de tais variáveis. Outro aspecto importante é que, devido à idade das crianças, a melhora da fluência na reavaliação também sofreu influência da recuperação espontânea da gagueira que estes participantes apresentaram.

Estudos futuros com grupo controle também deverão ser realizados, considerando-se medidas objetivas de gravidade da gagueira, antes e após as orientações fonoaudiológicas.

\section{AGRADECIMENTOS}

À Fundação de Apoio à Pesquisa do Estado de São Paulo (FAPESP), pela bolsa de iniciação científica concedida para realização deste projeto, processo número 2005/00147-5.

\begin{abstract}
Purpose: To determine the contribution of short-term familiar counseling in the speech fluency of children who stutter. Methods: Participants were 20 dyads of child who stutters and a family member. Procedures were carried out in three stages: assessment of fluency, familiar counseling, and reassessment of fluency. The initial assessment of fluency was performed in order to characterize the type and frequency of disfluencies produced before counseling. The familiar counseling was held in two sessions, emphasizing the verbal and non-verbal behaviors of family that can promote fluency in children. The reassessment of fluency occurred after thirty days, using the same procedures of the initial assessment. The Wilcoxon signed-rank test was applied to measure the significance level between data obtained in the two stages. Results: Regarding typology, comparative analysis of the two assessments showed that, among the six types of stuttering-like-disfluencies (SLD), five had presented reduction, and among the six types of other disfluencies (OD), four had diminished. With regards to the frequency of ruptures, $70 \%$ of the children had a reduction in the percentage of discontinuity of speech, and $80 \%$ in the total number of stuttering-like disfluencies. Conclusion: Familiar counseling sessions favored the fluency promotion in the speech of children who stutter, proving to be relevant in the childhood fluency area.
\end{abstract}

Keywords: Stuttering; Child; Counseling; Family

\title{
REFERÊNCIAS
}

1. Perkins WH. What is stuttering? J Speech Hear Disord. 1990;55(3):37082.

2. Leeper LH, Culatta R. Speech fluency: effect of age, gender and context. Folia Phoniatr Logop. 1995;47(1):1-14.

3. Zackheim CT, Conture EG. Childhood stuttering and speech disfluencies in relation to children's mean length of utterance: a preliminary study. $\mathrm{J}$ Fluency Disord. 2003;28(2):115-41

4. Zebrowski PM. Temporal aspects of the conversations between children who stutter and their parents. Top Lang Disord. 1995;15(3):1-17.

5. Ingham JC, Riley G. Guidelines for documentation of treatment efficacy for young children who stutter. J Speech Lang Hear Res. 1998;41(4):753-70.

6. Campbell J, Hill D. Systematic disfluency analysis. In: Northwestern University \& Stuttering Foundation of America. Stuttering therapy.
Memphis: Northwesternn University \& Stuttering Foundation of América; 1998. p. 51-75.

7. Zackiewicz DV. Avaliação quantitativa e qualitativa das disfluências em indivíduos gagos e fluentes [dissertação]. São Paulo: Universidade de São Paulo, Faculdade de Medicina; 1999.

8. Wittke-Thompson JK, Ambrose N, Yairi E, Roe C, Cook EH, Ober C, et al. Genetic studies of stuttering in a founder population. J Fluency Disord. 2007:32(1):33-50.

9. Yairi E, Ambrose NG. Early childhood stuttering: for clinicians by clinicians. Austin: Pro-Ed; 2005.

10. Starkweather CW, Gottwald SR. The demands and capacities model II: clinical applications. J Fluency Disord. 1990;15:143-157.

11. Manning WH. The demands and capacities model. J Fluency Disord. 2000;25:317-9 
12. Siegel GM. Demands and capacities or demands and performance? J Fluency Disord. 2000;25:321-7.

13. Adams M. The demands and capacities model I: theoretical elaborations. J Fluency Disord. 1990;15:135-141.

14. Savelkoul EM, Zebrowski PM, Feldstein S, Cole-Harding S. Coordinated interpersonal timing in the conversations of children who stutter and their mother and fathers. J Fluency Disord. 2007;32:1-32.

15. Oliveira CM, Araujo FG, Vocurca MC. Atitudes verbais e não verbais de pais de crianças com queixa de gagueira. Rev Soc Bras Fonoaudiol. 2000;5(7):3-10.

16. Andrade CR. Gagueira infantil: risco, diagnóstico e programas terapêuticos. Barueri: Pró Fono; 2006.

17. Davis S, Howell P, Cook F. Sociodynamics relationships between children who stutter and their non-stuttering classmates. J Child Psychol Psychiatry. 2002;43(7):939-47.

18. Blood GW, Blood IM. Bullying in adolescents who stutter: communicative competence and self-esteem. Contemp Issues Commun Sci Disord. 2004;31:69-79.

19. Healey EC, Trautman LS, Susca M. Clinical applications of a multidimensional approach for the assessment and treatment of stuttering. Contemp Issues Commun Sci Disord. 2004;31:40-48.

20. Murphy WP, Yaruss JS, Quesal RW. Enhancing treatment for schoolage children who stutter I. Reducing negative reactions through desensitization and cognitive restructuring. J Fluency Disord. 2007;32(2):121-38.
21. Yairi E, Ambrose NG. Early childhood stuttering I: persistency and recovery rates. J Speech Lang Hear Res. 1999;42(5):1097-112.

22. Meyers SC. Interactions with pre-operational pre-school stutterers: how will this influence therapy. In: Rustin L. Parents, families and the stuttering child. Kidworth: Far Communications; 1991. p. 40-58.

23. Guidelines for practice in stuttering treatment. Special Interest Division on Fluency and Fluency Disorders American Speech-Language-Hearing Association. ASHA Suppl. 1995;37(3 Suppl 14):26-35.

24. Oliveira CM, Curriel DT, Ferreira AC, Silva GA, Paziam L. Achados fonoaudiológicos da história clínica de crianças com queixa de gagueira. Fono Atual. 2002;5(21):30-5

25. Zebrowski PM, Kelly EM. Manual of stuttering intervention. Clifton Park (NY): Thomson Learning; 2002.

26. Guitar B. Stuttering: an integrated approach to its nature and treatment. Philadelphia: Williams \& Wilkins; 2006.

27. Harris V, Onslow M, Packman A, Harrison E, Menzies R. An experimental investigation of the impact of the Lidcombe Program on early stuttering. J Fluency Disord. 2002;27(3):203-13.

28. Rousseau I, Packman A, Onslow M, Harrison E, Jones M. An investigation of language and phonological development and the responsiveness of preschool age children to the Lidcombe Program. J Commun Disord. 2007;40(5):382-97.

29. Andrade CR. Fluência. In: Andrade CR, Béfi-Lopes DM, Fernandes FD, Wertzner HF. ABFW: teste de linguagem infantil nas áreas de fonologia, vocabulário, fluência e pragmática. 2a ed. Barueri (SP): Pró-Fono; 2000. p.61-9.

Anexo 1. Orientação fonoaudiológica para familiares de crianças com gagueira

Quais os tipos de quebras na fala (disfluências) que a criança apresenta? Faça um X no quadradinho:
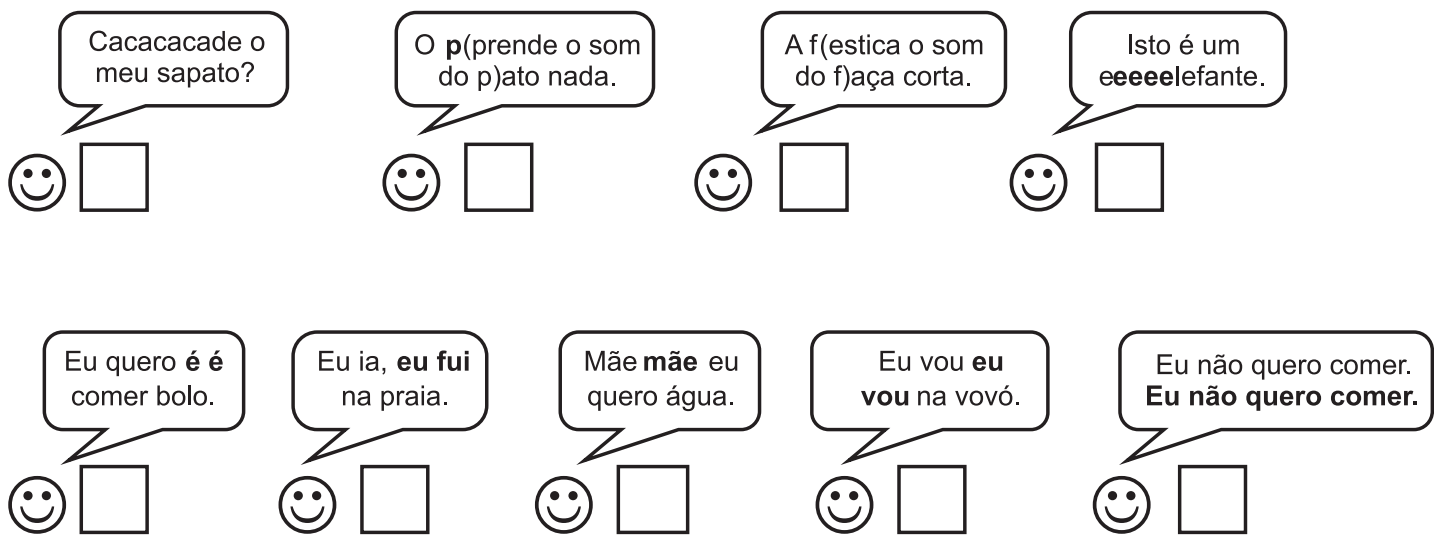

Você deve ter notado que a fala da criança pode ser interrompida ou enroscada devido á dificuldade que ela tem em falar de forma contínua (sem parar no começo ou no meio da palavra). Vários tipos de quebras (disfluências) podem acontecer na fala. Caso você tenha marcada os $\mathrm{X}$ na maioria dos desenhos da segunda linha, provavelmente a criança está passando por um período de disfluências comuns, e não gagueira. As disfluências ocorrem por vários motivos, como: dúvida na escolha da palavra ou no uso correto da gramática, e são utilizadas para organizar o pensamento, entre outros motivos. Estas disfluências vão diminuindo conforme a criança vai adquirindo a fala e a linguagem.

Se a fala da criança for interrompida freqüentemente pelas disfluências descritas na primeira linha, possivelmente a criança apresenta gagueira. Em alguns casos a criança poderá apresentar movimentos associados com o corpo, como piscar os olhos, movimentar a cabeça para frente, junto com o problema na fala.

Para ajudar a criança a diminuir estas quebras na fala, serão apresentadas algumas orientações:

1. Deixe a criança falar livremente, escute com paciência o que ela tem a dizer. Mostre que você está prestando atenção no que ela tem para dizer e não no modo como ela está falando.

2. Converse com a criança numa velocidade de fala lenta, pausando a fala sempre que necessário. Você pode começar a diminuir a velocidade de fala lendo um livro de estórias bem devagar, esticando ou prolongando as vogais, pausando nas vírgulas, pontos finais e outros sinais de pontuação. 
3. Fale de uma forma suave com a criança, demonstrando que para falar não é necessário usar tensão ou força dos músculos da boca e da garganta.

4. Não interrompa a fala da criança, pois assim ela perderá a seqüência do pensamento.

5. Use palavras simples e frases curtas.

6. Quando necessário, faça uma pergunta por vez para a criança, esperando que ela responda, pois perguntas feitas ao mesmo tempo podem confundir a criança.

$\checkmark$ Não chame a criança de gaga, pois irá prejudicá-la, podendo favorecer a sua identificação como gaga.

$\checkmark$ Mantenha o contato de olho natural enquanto ela estiver falando.

$\checkmark$ Ofereça oportunidades para a criança falar sem competição e distração de outras pessoas.

$\checkmark$ Prepare a criança para atividades e situações que irão ocorrer durante um passeio, férias ou festa de aniversário. Por exemplo, comente sobre as pessoas que irão encontrar,...

$\checkmark$ Se a criança não for consciente do problema, não chame a atenção para este fato. Se for consciente não tente protegê-la pela pretensão de que sua fala é normal. É melhor conversar abertamente sobre as dificuldades da criança.

$\checkmark$ Tente agir da mesma maneira quando sua criança for disfluente ou fluente.

$\checkmark$ Conte estórias para a criança, se ela quiser deixe-a completar as frases ou terminar a estória que já conhece.

$\checkmark$ Procure expressar sentimentos positivos não verbais, olhe para ela e sorria, dê carinho, mostre que você tem orgulho dela.

$\checkmark$ Não compare a fala de uma criança que gagueja com a de outros filhos, primos e outras crianças.

Inicie gradativamente as mudanças necessárias na sua fala e no ambiente, dedicando no começo 5 a 10 minutos de cada período do dia para colocá-las em prática. Depois, vá aumentando o tempo até que você use continuamente estes novos modelos e atitudes.

\section{Como melhorar minha fala para ajudar a criança a diminuir a gagueira?}

Para melhorar o modelo de fala que criança está exposta é necessário diminuir a velocidade de fala, movimentar a boca de forma bem suave e emendar as palavras pausando sempre que necessário.

Vamos falar algumas palavras suavizando o início das palavras, esticando as vogais das sílabas e emendando as sílabas:
pa.....to....
bo....la.....
fa.....ca....
ma....la....
ma...ca....co...
pa....ne...la....
pi....po.....ca....
fo....gue....te....

Nas frases simples devemos dar continuidade entre as sílabas e entre as palavras, ou seja, emendamos os sons suavemente:

O....pa....to....na....da.... (falamos tudo numa saída de ar)

O....ga....to....mi..........

A....fa....ca....cor....ta....

O....ca....rro....é.....ver....de....

A....ma....ça....é....ver....me.....lha....

Nas frases maiores, devemos emendar as sílabas e palavras até o sinal de vírgula ou ponto final:

O....me....ni....no...., * que....es....ta....va....no....par...que...., * ca....iu.....**

* $=$ pausa que deve ser dada, podendo ser usada para respirar.

${ }^{* *}$ = pausa maior (2 segundos) usada nos pontos finais, ou entre uma frase e outra.

E..ra..u..ma...vez.., ${ }^{\star}$ u..ma...me...ni...na..., ${ }^{*}$ cha...ma...da...cha...peu....zi....nho...ver...me...lho....**

Você percebeu como é possível diminuir a velocidade de fala esticando as sílabas e colocando algumas pausas na fala? Porém, é preciso muito treino e paciência. Algumas atividades são recomendadas para facilitar o uso da fala mais lenta, suave e emendada, como: jogo de memória, jogo de nomeação de objetos ou figuras, lince e contagem de estórias.

O modelo de fala mais lento dos familiares é importante porque a criança irá tentar imitar a sua maneira de falar, e quando falamos rápido o músculo fica mais duro (tenso) tornando mais difícil manter uma fala sem interrupção (disfluência). Outro motivo para estimular a criança a falar um pouco mais lento (mas não de forma artificial) é que ela está passando por um período de aprendizagem do uso das palavras e das frases, e se ela falar muito rápido possivelmente ela apresentará quebras (disfluências) na fala.

Os movimentos suaves da boca (lábios e língua) e dos músculos da garganta irão evitar a gagueira, pois todo momento que a criança gagueja apresenta um excesso de força. Freqüentemente as crianças gaguejam mais no início das palavras e por isso todo início da fala deve ser suavizado (falar sem força, sem tensão no músculo).

A fala contínua também auxilia na diminuição da gagueira, pois diminui o número de inícios da fala, local onde geralmente a gagueira ocorre.

Tente melhorar a qualidade de conversa (diálogo) que você tem com a criança. Escolha momentos calmos, tranqüilos para usar este tipo de fala, como na hora em que o nenê estiver dormindo, em que a televisão esteja desligada, no momento em que você não tiver pressa. 